\title{
Happiness of university students in new normal Malaysia: The role of mattering, optimism, and social support
}

\author{
ZeWai Foo, Kususanto Ditto Prihadi \\ Department of Psychology, HELP University, Kuala Lumpur, Malaysia
}

\begin{tabular}{l} 
Article Info \\
\hline Article history: \\
Received Oct 18, 2020 \\
Revised Feb 22, 2021 \\
Accepted Apr 11, 2021 \\
\hline
\end{tabular}

\section{Keywords:}

Happiness

Mattering

Optimism

Perceived social support

\begin{abstract}
Studies among students in higher education have established the sense of altering as one of the predictors of subjective well-being, which represents happiness. However, the transition from the quarantined period to the new normal lifestyle amidst the pandemic in Malaysia might have altered the way mattering predicts happiness. Some studies have reported that students tend to feel less socially supported during online studies, and not every one of them showed high optimism or the belief that a better situation will come soon. We hypothesized that in the new normal, the association between mattering and happiness is fully mediated by perceived social support and optimism. In order to test the hypothesis, 400 university students between 18 to 30 years of age were recruited to respond to the Satisfaction with Life Scale, Revised life orientation test, mattering to others questionnaire, and multidimensional scale of perceived social support. Analyses with Bootstrap method with 5,000 sampling and 95\% confidence interval using PROCESS Macro Model 4 yielded results, which suggested that mattering is still a robust predictor of happiness and that both perceived social support and optimism only partially mediated the association. Limitations and suggestions for future studies are discussed.
\end{abstract}

This is an open access article under the CC BY-SA license.

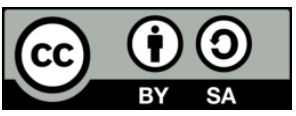

\section{Corresponding Author:}

Kususanto Ditto Prihadi

Department of Psychology

HELP University

Persiaran Cakerawala, Section U4, Shah Alam, Malaysia

Email: prihadi.k@help.edu.my

\section{INTRODUCTION}

Mattering refers to the sense of being significant and important to other people [1], [2]. In general context, it holds significant roles in social interactions; for instance, individuals with higher levels of mattering would likely to develop a better state self-esteem, and hence better satisfaction in life among social media users [3], and in the context of university students, mattering was reported to be a significant protective factor towards depression symptoms and suicide ideation [4]. In general, mattering is reported to be a significant predictor of psychological well-being among university students [5]. To be more specific, the significance of mattering lies on its predictive role on the university students' happiness [6]-[8] because when one believes that they matter to others around them, they will subjectively feel that they are doing well. We conducted this study to reconfirm whether during the 'new normal' (post-quarantine situation amidst the pandemic), happiness among university students is still significantly predicted by their sense that they matter to others, knowing that their social interaction has been changed by the nature of the quarantine and social distancing [9]. 
During the movement control order (MCO) amidst the pandemic between March and June 2020, and October, 2020, most residents of Malaysia were quarantined situation and most of the activities were conducted online. In such situation, social interaction among university students was altered. First, the size of the physical social environment was changed; those who used to live closely with many others in commonly rented apartments or resident halls needed to move to their homes, where other individuals might have less common interests with them; a study before pandemic suggested that university stakeholders who resided in a more crowded living space tend to develop lower levels of mattering [10]. As the development of mattering is based on our relationship with those who surround us, changes in their numbers and nature of relationship might also alter the mattering levels.

Second, they became more inclined towards digital communication [11] as social interactions, such as classes, consultations, meetings and events were held through online medium. In any form, higher reliance towards digital communication might have different social impacts as digital interactions were almost always premediated or expected before it took place [12], [13]. In other words, digital social interaction reduces the possibilities of receiving spontaneous social feedback from accidental or unplanned encounter with other people. Moreover, most members of the society tend to put socially accepted profile in their social media account or any digital communication platform, the social feedback they received tend to be more positive than when the encounter occurred non-digitally [14].

Symbolic Interaction theory [15] explained that positive social feedback tends to lead us to evaluate ourselves more positively and increase the feeling that we matter to others who provided us with their feedbacks. In line with that, elements of mattering are developed based on social feedback, such as acknowledgment of being present and reliable [2] as well as being unique and irreplaceable [1]. Related to that, in order to reconfirm the robustness of mattering in predicting happiness among university students in the new normal, we would like to involve two mediator variables, namely perceived social support and optimism.

Perceived social support (PSS) was chosen as mediator for two reasons, first because it is a significant predictor of happiness [16]-[18], and second, it is positively related to the sense of mattering [19]. In other words, when one believes that they matter to others, they would likely to perceive that they are socially supported, and eventually this will lead them to a greater happiness. Optimism is chosen through similar justification; it predicts happiness [20], and predicted by mattering [21]. Thereby, we hypothesized that there perceived social support and optimism will fully mediate the contribution of mattering on happiness among university students, or in other words, when students believe that they matter to other people around them, they would likely to develop higher optimism, and belief that they are supported by the society, and in turn, these two feeling will lead them to develop higher sense of happiness or subjective wellbeing.

Previous studies indicated that the sense that one matters to others significantly predict happiness or SWB [6] and it is considered as an important evaluative guidance to compare one's social positions to others [1]. A study among college students in the United States reported that mattering explains the robustness of friends' social support in predicting happiness [22], in other words, they reported that students who perceived that they received more social support from their friends tend to believe that they matter more and thus believe that they are happy. In line with that, another study among Turkish college students indicated that mattering predicted their happiness, mediated by friendship quality [23]. Another study in Asian context yielded the same results, where happiness, as a part of psychological well-being among university students, was reported to be significantly predicted by their sense that they matter to others and to their respective universities. Nevertheless, despite the regency, the two aforementioned studies were conducted before the global pandemic pushed most of the college students to study online; therefore, it can be assumed that their senses of mattering were not resourced mostly from digital communication. It is important to note that there is an enormous gap in terms of mindset among most people before and after pandemic, especially for those who live in the place that enforced quarantine policy [9].

Our review on the previous studies indicated that the new normal might alter individuals' mattering because of several reasons: first, there was a significant change in the number of people living around them; a study among Texan universities with large stakeholders has established that the size of the immediate social environment was negatively related to their mattering, which means that the larger the number of their immediate social size, the lower they would sense that they matter [10]. It was explained because one of the functions of mattering, missed when absent [1], might not be emphasized in larger society, same as the uniqueness and importance. Second, the pandemic put many university students, who are mostly in the lowrisk category of COVID, into believing that they mattered more to their significant others who need their care and attention, especially those with higher COVID risk [9]. Lastly, individuals were more connected to social media, where they received more desirable social feedback due to their tendency to frame themselves in a manner that attracts such social feedback [11], and eventually, mattering significantly predicted happiness

Happiness of university students in new normal Malaysia: The role of mattering, optimism ... (ZeWai Foo) 
through state self-esteem among social media users [3]. The aforementioned studies indicated that mattering plays significant role in predicting happiness, either directly or indirectly; therefore, any alteration of mattering during the pandemic might also alter the happiness itself. Furthermore, the involvement of other variables that were likely to be altered by the pandemic, such as optimism and PSS might change the way mattering predicts happiness.

Optimism refers to the tendency to think of their future in a positive manner and expect that life will be generally favorable [18]. It is a cognitive construct, therefore it came through a thought process, instead of affective or emotional [24], therefore individuals with high optimism tend to see the logic that the achievement of a favorable future closely related to their present effort, while individuals with low optimism tend to avoid paying effort because the perceived association between their effort and favorable future is insignificant. Optimism has been reported to interact with self-efficacy a perceived social support in predicting happiness among the elderly [25] as well as among children refugees [26]. Further empirical evidence of the robustness of optimism in predicting happiness recently came from a study among middle school students in South Korea, where optimism was reported to fully mediated the association between stress and happiness [27].

While it is evident in many instances that optimism is a robust predictor of happiness, and it tend to be consistent in different times and situations [28], the work of Elizabeth and Chang in 2019 suggested that optimism is significantly predicted by the sense of mattering [21]; they reported that optimism was predicted by the interaction of mattering and presence of meaning of life for Asian American students and with searching for meaning of life for European American students. In sum, optimism was reported to be a significant predictor of happiness, and some other studies reported that mattering played significant predictive role to optimism, which led us to hypothesize that optimism might fully explain (mediate) the association between mattering and happiness. Testing the aforementioned hypothesis is important, because amidst the pandemic, individuals who are not immediately related to medical profession or policymaker might perceive that their future is less predictable, which means that they might develop lower optimism levels [9].

In the context of college students, a study in South Korea yielded a result that when the students perceived that they receive supports from their parents and educators they will experience lower levels of depressive symptoms and greater happiness [29]. In another study with the same context, it was also reported that PSS fully explained the link between extraversion and happiness [30]. The aforementioned two studies claimed that when students perceived that their social environment is supportive, they would feel happier, less depressed, and the link between their trait extraversion and happiness would be stronger. It is an indication that in the context of college students, their happiness is significantly predicted by the perception that they are supported by people around them.

Some studies showed evidence that mattering is a more robust predictor of happiness than PSS; a study among retirees disclosed that the feeling that their significant family members supported them will make them happy only when they feel they matter to their significant family members [19]. In other words, even though they felt the support, if they did not feel they matter, they would not develop any happiness. Similar findings were reported in the context of working adults and college students [16], [17], whereby individuals would not feel any happiness despite they understand that they are supported by their coworkers or educational stakeholders, until they feel that those people considered that they matter [17].

While the aforementioned study indicated different direction of predictive relationship between mattering and PSS, in this current study, we put mattering as our focal predictor, which will predict happiness through PSS for two reasons. First, the past studies that we reviewed used the data that was retrieved before the pandemic, whereby the source of mattering has been stable over years, and second, the presence of the pandemic itself drove individuals to develop their sense of mattering without the presence of PSS [9]. Thus, our next hypothesis was drawn based on the knowledge that the new normal had elevated the sense of mattering due to the perception that individuals believed that they mattered more to their significant others during pandemic [9] and that their inclination towards online social interaction, which gave them more positive social feedback [14]. We hypothesized that mattering will significantly predict higher PSS, which eventually lead to higher levels of happiness. Figure 1 illustrates the hypothetical model to be tested in this current study.

It is important to note that we do not hypothesize any interaction or statistical relationship between optimism and PSS because our literature suggested that both of them might mediate the association between mattering and happiness separately. Another important note is that this study is quantitative correlational, therefore despite we might collect some evidence of relationship; our findings do not imply any causal relationship between any pair of variables. 


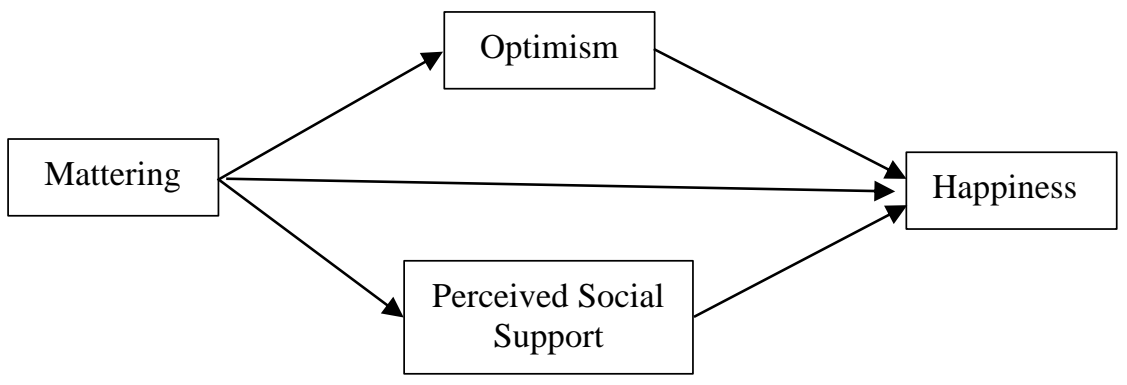

Figure 1. Hypothetical model

\section{RESEARCH METHOD}

\subsection{Participants}

We recruited 400 university students between 18 and 30 years of age to participate in this current study through purposive sampling. All of the participants were studying from home during the MCO and in the time where data was collected. A Google form containing an informed consent form, demographic questionnaire, and all the scales to gauge the variables was accessible through a link that was disseminated through our social media such as Facebook, Instagram, LinkedIn, WhatsApp, WeChat, Telegram, as well as emails.

\subsection{Scales}

The Revised Life Orientation Test (LOT-R) [31] was utilized to measure the level of optimism among our participants, while their levels of happiness were gauged by utilizing the satisfaction with life scale (SWLS), [32]. Mattering to others questionnaire (MTOQ) [33] where a higher mean total score indicates a greater level of perceived mattering was utilized to measure the sense of mattering, and the multidimensional scale of perceived social support (MSPSS) [34] where a higher mean score indicates higher levels of perceived social support was employed to measure the PSS. Reliability (Cronbach's Alpha) of each scale were $.76, .82, .93$, and .72 respectively.

\section{RESULTS AND DISCUSSION}

The analyses were conducted by utilizing PROCESS Macro model 4 because we opted to conduct the analyses with Bootstrap method in order to see the significance of the mediation effects. The Bootstrap was conducted with 5,000 samplings at 95\% confidence interval. Table 1 indicates that mattering significantly predict both mediators.

Table 1. Mattering as a significant predictor of the mediators

\begin{tabular}{ccccccc}
\hline & $\mathrm{R}^{2}$ & $\beta$ & $\mathrm{F}$ & $\mathrm{p}$ & $\mathrm{df1}$ & $\mathrm{df2}$ \\
\hline Optimism & .13 & 2.32 & 59.07 & .00 & 1.00 & 398.00 \\
PSS & .31 & .81 & 179.51 & .00 & 1.00 & 398.00 \\
\hline
\end{tabular}

Table 1 presents that mattering is a stronger predictor for optimism than PSS, because one point of increment in mattering predicts 2.32 points of increase in optimism and 0.81 points in PSS. However, the contribution of mattering is more prevalent in PSS, because it explained $31 \%$ of variance in PSS and only $13 \%$ of variance in optimism. Despite the difference, it is still indicated that statistically, mattering is a salient predictor of both PSS and optimism. Furthermore, Table 2 informs the effect of each variable on happiness when controlling for the rest.

Table 2. Mattering as a significant predictor of the mediators

\begin{tabular}{ccccccc}
\hline & $\beta$ & $\mathrm{se}$ & $\mathrm{t}$ & $\mathrm{p}$ & LLCI & $\mathrm{ULCI}$ \\
\hline Mattering & .52 & .41 & 1.26 & .21 & -.29 & 1.33 \\
Optimism & .53 & .06 & 9.73 & .000 & .43 & .64 \\
PSS & 1.73 & .28 & 6.27 & .000 & 1.19 & 2.27 \\
\hline
\end{tabular}


From Table 2, we can see that mattering is no longer a significant predictor of happiness among university students during the new normal when controlling for optimism and PSS. Table 3 shows how mattering predicts happiness through optimism and PSS. It is important to note that we used PROCESS Macro model 4 (for multiple mediation) instead of model 6 (for serial mediation), because our literature did not justify any predictive relationship between PSS and optimism; therefore, in the context of this study, the mediation roles of optimism and PSS are assumed to occurred simultaneously yet separately.

Table 3. The indirect effect of mattering on happiness through optimism and PSS

\begin{tabular}{ccccc}
\hline & $\beta$ & BootSE & BootLLCI & BootULCI \\
\hline Optimism & 1.24 & .19 & .85 & 1.62 \\
PSS & 1.40 & .28 & .88 & 1.98 \\
\hline
\end{tabular}

Table 3 indicates that both optimism and PSS are the significant mediators of the association between mattering and happiness. The gap between upper and lower limit of confident interval for both mediators did not contain zero, which indicated that no effect among the 5000 Bootstrap samplings shows insignificance. In other words, our findings lead us to conclude that in the new normal situation in Malaysia, students' mattering did not significantly predict their happiness any longer, unless it predicted their sense of optimism and perception that they are socially supported.

Our findings indicated that both optimism and PSS fully mediated the association between mattering and happiness among university students in the new normal. In other words, while the new normal might have elevated the students' mattering due to the smaller size of immediate others [10], feeling towards significant others with higher COVID risks [9] and higher reliance to digital communication through social media [3], [11], [14], it will not immediately elevate their likelihood to be happier before the elevation of their mattering brought positive changes to their optimism and PSS.

It is worthwhile to review the differences of the natures of our study and the previous ones. In our study, the most salient factor could have been the new normal and the inclusion of PSS and optimism. For instance, few years before the pandemic, Demir, et al. [23] reported that mattering was the significant mediator of the association between friendship quality and happiness, which means that the friendship quality should elevate the mattering first before eventually mattering, increased the level of happiness, and there was no mediating variable reported between mattering and happiness. This difference might occur as optimism, as defined as the tendency to believe that the future holds desirable outcomes [18], might be assumed to be dispositionally stable before the pandemic and the new normal, hence the exclusion in the study.

Findings of this currents study is in line with the findings of Sim and Prihadi, who reported that mattering lost its significance in predicting happiness when controlling for state self-esteem [3]. The difference was that while they prefer to explain the link between mattering and happiness with state selfesteem, we were more interested to see how optimism and PSS accounted for the same link. It is somehow suggested for future study to investigate the link between state self-esteem and optimism or PSS, because the three variables were similarly able to explain the link between mattering and happiness. It would be imperative to see which one among the three is the robust predictor.

\section{CONCLUSION}

The study concluded that mattering is still a robust predictor of happiness and that both perceived social support and optimism only partially mediated the association. The knowledge that we have obtained from this current study suggested that keeping the stability of PSS and optimism is significant to keep university students in an adequate happiness level. In other words, it is important to keep the students to feel that other people around them are supportive as well as to keep them able to see that the situation in the near future will be more desirable than today. Amidst the new normal, where the social interaction and resources are limited, it might be easier for educational stakeholders to pay more effort to improve students' sense of mattering. Moreover, an improved sense of mattering predicts higher optimism and PSS, which eventually elevate happiness level. Thus, it is highly suggested to the stakeholders of higher education to treat students with increasing their mattering in mind; the communication to the students should make students feels that their presence and reliability are acknowledged, as well as their being unique and irreplaceable.

\section{ACKNOWLEDGEMENTS}

This study is funded by the Internal Research Grant Scheme from HELP University \# 20-07-024. 


\section{REFERENCES}

[1] G. Flett, The psychology of mattering: Understanding the human need to be significant. Academic Press, 2018.

[2] M. Rosenberg and B. C. McCullough, "Mattering: Inferred significance and mental health among adolescents," Research in Community \& Mental Health, vol. 2, pp. 163-182, 1981.

[3] P. P. Sim and K. Prihadi, "They Logged-in, Compared, and Satisfied: Serial Mediation of Mattering and State Selfesteem on the Link between Social Comparison and Life Satisfaction," International Journal of Public Health Science (IJPHS), vol. 9, no. 3, pp. 245-254, 2020.

[4] K. D. Prihadi, C. Y. Wong, E. Y. Chong and K. Y. Chong, "Suicidal Thoughts among University Students in Malaysia and Indonesia: The Role of Mattering, State Self-Esteem and Depression Level," International Journal of Evaluation and Research in Education (IJERE), vol. 9, no. 3, pp. 494-502, 2020.

[5] G. Flett, A. Khan and C. Su, "Mattering and Psychological Well-being in College and University Students: Review and Recommendations for Campus-Based Initiatives," International Journal of Mental Health and Addiction, vol. 17, pp. 667-680, 2019, doi: 10.1007/s11469-019-00073-6.

[6] G. Elliott, S. Kao and A.-M. Grant, "Mattering: Empirical Validation of a Social-Psychological Concept," Self and Identity, vol. 3, no. 4, p. 339-354, 2004.

[7] C. Matera, N. Bosco and P. Meringolo, "Perceived Mattering to Family and Friends, Self-Esteem, and WellBeing," Psychol Health Med., vol. 25, no. 5, pp. 550-558, 2020.

[8] H. Taniguchi, "Interpersonal Mattering in Friendship as a Predictor of Happiness in Japan: The Case of Tokyoites," Journal of Happiness Studies, vol. 16, no. 6, pp. 1475-1491, 2015.

[9] S. Casale and G. L. Flett, "Interpersonally-based fears during the covid-19 pandemic: Reflections on the fear of missing out and the fear of not mattering constructs," Clinical Neuropsychiatry, vol. 17, no. 2, p. 88-93, 2020.

[10] J. C. Stoner and Y. Zhang, "Resident Assistant Mattering: Do Placement and Community Size Matter?" Journal of College \& University Student Housing, vol. 43, no. 2, pp. 28-43, 2017.

[11] M. Tsay-Vogel, J. Shanahan and N. Signorielli, "Social media cultivating perceptions of privacy: A 5-year analysis of privacy attitudes and self-disclosure behaviors among Facebook users," New Media \& Society, vol. 20, no. 1, pp. 141-161, 2018.

[12] L. Bareket-Bojmel, S. Moran, and G. Shahar, "Strategic self-presentation on Facebook: Personal motives and audience response to online behavior," Computers in Human Behavior, vol. 55, pp. 788-795, 2016.

[13] E. A. Vogel, J. P. Rose, B. M. Okdie, K. Eckles and B. Franz, "Who compares and despairs? The effect of social comparison orientation on social media use and its outcomes," Personality and Individual Differences, vol. 86, pp. 249-256, 2015.

[14] A. K. Przybylski, K. Murayama, C. R. DeHaan, and V. Gladwell, "Motivational, emotional, and behavioral correlates of fear of missing out," Computers in Human Behavior, vol. 29, pp. 1841-1848, 2013.

[15] N. Aksan, B. Kısac, M. Aydın, and S. Demirbuken, "Symbolic interaction theory," Procedia-Social and Behavioral Sciences, vol. 1, no. 1, pp. 902-904, 2009.

[16] C. F. Ratelle, K. Simard, and F. Guay, "University students' subjective well-being: The role of autonomy support from parents, friends, and the romantic partner," Journal of Happiness Studies, vol. 14, no. 3, pp. 893-910, 2013.

[17] K. L. Siedlecki, T. A. Salthouse, S. Oishi, and S. Jeswani, "The Relationship between Social Support and Subjective Well-Being across Age," Social Indicators Research, vol. 117, no. 2, pp. 561-576, 2014.

[18] C. S. Carver, M. F. Scheier, and S. C. Segerstrom, "Optimism," Clinical Psychology Review, vol. 30, no. 7, pp. 879-899, 2010.

[19] A. Froidevaux, A. Hirschi, and M. Wang, "The role of mattering as an overlooked key challenge in retirement planning and adjustment," Journal of Vocational Behavior, vol. 94, pp. 57-69, 2016.

[20] T. Dinisman, A. Zeira, Y. sulimani Aidan, and R. Benbenishty, "The subjective well-being of young people aging out of care," Children and Youth Services Review, vol. 35, no. 10, pp. 1705-1711, 2013.

[21] A. Y. Elizabeth and E. C. Chang, "Meaning in life as a predictor of optimism: How parents mattering matters to Asian and European Americans," Personality and Individual Differences, vol. 138, pp. 366-369, 2019.

[22] A. D. Rayle and K. Y. Chung, "Revisiting first-year college students' mattering: Social support, academic stress, and the mattering experience," Journal of College Student Retention: Research, Theory \& Practice, vol. 9, no. 1, pp. 21-37, 2007.

[23] M. Demir, A. Özen, and A. Doğan, "Friendship, Perceived Mattering and Happiness: A Study of American and Turkish College Students," The Journal of Social Psychology, vol. 152, no. 5, pp. 659-664, 2012.

[24] C. S. Carver and M. F. Scheier, "Optimism," in Handbook of Positive Psychology, New York, Oxford: University Press, 2005, pp. 231-256.

[25] R. Lara, M. L. Vázquez, A. Ogallar, and D. Godoy-Izquierdo, "Optimism and social support moderate the indirect relationship between self-efficacy and happiness through mental health in the elderly," Health Psychology Open, vol. 7, no. 2, pp. 1-12, 2020.

[26] G. Veronese, M. Castiglioni, M. Tombolani and M. Said, "'My happiness is the refugee camp, my future Palestine': optimism, life satisfaction and perceived happiness in a group of Palestinian children," Scandinavian Journal of Caring Sciences, vol. 26, no. 3, pp. 1-7, 2012.

[27] T. E. Kim, "The Mediating Effect of Optimism on the Relationship Between Stress and Happiness at School Perceived by Middle School Students," Journal of Digital Convergence, vol. 17, no. 2, pp. 413-421, 2019

[28] Q.-Q. Liu, Z.-K. Zhou, X.-J. Yang, G.-F. Niu, Y. Tian and C.-Y. Fan, "Upward social comparison on social network sites and depressive symptoms: A moderated mediation model of self-esteem and optimism," Personality and Individual Differences, vol. 113, pp. 223-228, 2017. 
[29] C. H. Bum and I. K. Jeon, "Structural relationships between students' social support and self-esteem, depression, and happiness," Social Behavior and Personality: An International Journal, vol. 44, no. 11, pp. 1761-1774, 2016.

[30] C. S. Tan, S. K. Low and G. N. Viapude, "Extraversion and happiness: The mediating role of social support and hope," PsyCh Journal, vol. 7, no. 3, pp. 133-143, 2018.

[31] M. F. Scheier, C. S. Carver and M. W. Bridges, "Distinguishing optimism from neuroticism (and trait anxiety, selfmastery, and self-esteem): a reevaluation of the Life Orientation Test," Journal of Personality and Social Psychology, vol. 67, no. 6, pp. 1063-1078, 1994.

[32] E. Diener, R. A. Emmons, R. J. Larsen and S. Griffin, "The Satisfaction with Life Scale," Journal of Personality Assessment, vol. 49, no. 1, pp. 71-75, 1985.

[33] S. K. Marshall, "Do I Matter? Construct validation of adolescents' perceived mattering to parents and friends," Journal of Adolescence, vol. 24, no. 4, pp. 473-490, 2001.

[34] G. D. Zimet, N. W. Dahlem, S. G. Zimet and G. K. Farley, "The Multidimensional Scale of Perceived Social Support,” Journal of Personality Assessment, vol. 52, no. 1, pp. 30-41, 1988. 